Original Article

\title{
OBSERVATIONAL STUDY ON POISON CASES IN A TERTIARY CARE HOSPITAL
}

\author{
RAMYA A. ${ }^{1 *}$, ANDHUVAN G. ${ }^{1}$, RAGHUPATHI V. ${ }^{2}$ \\ ${ }^{1}$ Department of Pharmacy Practice, PSG College of Pharmacy, Coimbatore, Tamilnadu, India, ${ }^{2}$ Emergency Department, PSG Hospitals, \\ Coimbatore, Tamilnadu, India \\ Email: ramibpharm@gmail.com
}

Received: 10 Aug 2018 Revised and Accepted: 22 Feb 2019

\section{ABSTRACT}

Objective: To evaluate the prevalence, pattern, and cause of poisoning. To characterize the poisoning cases admitted in a tertiary care hospital; followed by the outcome and to observe the antidote given for the poison cases.

Methods: This observational study was undertaken in emergency departments (EMD) and Medical Record Department (MRD). Totally 557 poison cases was recruited in this study. Grade of poison was assessed by using poison severity score. Statistical analysis was done by using Statistical Package for Social Sciences (SPSS).

Results: A total of 557 poison cases were identified in 2, 39, 828 patients out of which 360(64\%) were suicidal and 189(34) cases admitted were accidental. The patients who were admitted between $2-5 \mathrm{~h}$ after exposed to poison were found to be more followed by $0-1 \mathrm{hr},>1-2 \mathrm{~h},>6-24 \mathrm{~h},>24 \mathrm{~h}$ and $>5-6 \mathrm{~h}$. More number of cases were seen in the others (Synthetic cow dung powder and medicine) type of poison 296(53\%) followed by household poisoning $93(17 \%)$, bites 86 (15\%), insecticide poisoning $64(12 \%)$ and food poisoning $16(3 \%)$. Activated charcoal was the maximum used antidote.

Conclusion: Through this study, it was found that suicidal poisoning was the most common type.

Keywords: Poison, Prevalence, Antidote

(c) 2019 The Authors. Published by Innovare Academic Sciences Pvt Ltd. This is an open-access article under the CC BY license (http://creativecommons.org/licenses/by/4.0/) DOI: http://dx.doi.org/10.22159/ijpps.2019v11i4.27603

\section{INTRODUCTION}

Poison is defined as an agent which can kill, injure or harm the normal physiological function of the human beings. Poison is one of the major causes for the death worldwide [1].

Among the Poisoning due to accidental or deliberate ingestion inhalation of medicinal drugs and other chemicals, snake bite is also one of the acute common medical emergencies for the increased mortality rate. So, information regarding the types of snakes available in those particular zones and suitable antidote for that snake bite will help the physicians to give treatment at right time and to prevent the organ failure caused by that poisonous snake bite.

An increase incidence of pesticide poisoning was seen in some retrospective hospital-based studies and some surveillance reports. Sometimes, accidental and suicidal poisoning along with the high morbidity and mortality rates seen in organophosphorus compounds. So we can able to reduce these incidences by implementing the community programs, upgrading and strengthening the toxicological units in the public health care centres, and counselling from the psychiatric specialist at the affordable cost [2].

Among the other poisonings, medicine poison is considered as one of the important medical condition. It seems accidental poisoning in children with improper use of therapeutic drugs like over intake of tablets or because of the improper storage of the drugs by the elders [3]. The main reason for increasing incidences of poison was cheaper cost and easy accessibility of the hazardous chemicals plays one of the specific roles for the increasing rate of accidental and suicidal poisonings [4].

Among the other poisonous substances, one of the important poison noted in this community is the rodenticides (Aluminium phosphide, Yellow phosphorous, zinc phosphide) [5].

Followed by plant poisonings like oleander seeds, calotropis were seen mostly in adults and elder patients. Oleander is a Toxic Cardiac Glycoside found in Oleander (Nerium oleander L.) The uncrushed seeds of oleander will use for the suicidal purpose, it will cause vomiting and loose stools and the patient will die because of volume loss if left untreated. These kinds of poisoning were mostly seen in the village areas.

Cow dung, which has a germicidal property and insect repellents being used to clean homes and temples in south India. But nowadays synthetic cow dung powders were available since the unavailable of natural cowdung; which are locally called as "Saani Powder" in local Tamil language. They are readily available in the shops as well as in the homes [6].

So, the determination of own poison profile in every region is mandatory and should take necessary measures against possible risks.

\section{MATERIALS AND METHODS}

Study site

This study was conducted at PSG Hospitals, Peelamedu, Coimbatore.

Study approval

This study was approved by the Institution Human Ethics Committee (IHEC, PSG IMS andR) of the hospital. The protocol was approved on 01.12.2017, Proposal number: 17/322.

\section{Study design}

This observational study was conducted to evaluate the prevalence of acute poisoning cases admitted in emergency departments and medical record department of PSG hospitals, Coimbatore, Tamilnadu.

\section{Study period}

The study was conducted for a period of $1 \mathrm{y}$.

\section{Study subjects}

The study includes in-patients of poison cases under treatment. Both gender and all age groups were included. Patients discharged against medical advice and incomplete medical data were excludedtudy materials. 
Patient data collection form: it includes demographic details of the patient like IP number, age, sex, the cause of exposure, type of poison, antidote chart, outcome.

\section{Study procedure and collection of data}

A retrospective (Jan 2012 to Nov 2017) and prospective (December 2017 to March 2018) analysis of all the poison cases who admitted in the emergency departments and from there to shifted wards in PSG Hospitals.

This involved all inpatients who presented with the acute poisonings of intentional, occupational, and accidental of all age groups. People who were under $7 \mathrm{y}$ of age are recruited as "Subjects" after their poisoning events were confirmed by caregivers following the initial evaluation at the hospital's emergency department. Patients admitted for cow dung powder poisoning, corrosives, Organophosphates (Rodenticides and Pesticides), Ant killer, Medicines, snake bite, food, Plant poisonings, and household chemicals were also included in this study.

\section{Data collection}

After approval of the Institutional Human Ethics Committee (IHEC) of PSG IMSandR (NO. 17/322), the study was carried out based on inclusion and exclusion criteria. Totally 557 cases were recruited over the $1 \mathrm{y}$ period. Data based on the demographic factors were recorded. The severity of the poison has been assessed based on the 4 grades (Grading scale) based on the Poisoning Severity Score. Grading of acute Poisoning which was framed by clinical toxicology. Swedish Poison Information Centre, Stockholm, Sweden (HP, GS); International Programme on Chemical Safety, WHO, Geneva, Switzerland (JH, JP).

1) None, 2) Minor, 3) Moderate, 4) Severe

Grades

NONE: No symptoms/signs related to the poisoning
MINOR: Mild, transient, and spontaneously resolving symptoms/signs.

MODERATE: Pronounced/prolonged symptoms/signs

SEVERE: Life-threatening symptoms/signs.

FATAL: Death

\section{Statistical analysis}

All analysis was performed with Statistical Package for Social Sciences (SPSS) version 16 program. Categorical variables were described as percentages and some data were compared by chisquare test and significance was analysed by $p$-value.

\section{RESULTS}

Prevalence of poison each year with the number of poison cases

A total of 557 poison cases were identified during the study period. So based on each year, in 2012(0.19\%) cases, 2013(0.21\%), 2014 (0.20\%), 2015(0.29\%), 2016(0.24\%), 2017(0.19\%), 2017, 2018(1\%). From this, 2012 and 2017 equal amount of poison patients were seen. Totally, 557 cases $(0.23 \%)$ were seen in the 75 mo of data.

\section{Gender wise distribution of poison cases}

Out of 557 cases, 242 cases were males and 315 cases were females. Female patients were predominant over the male patients.

\section{Age group classification}

Out of 557 subjects, based on the age group the total number of cases in child were $43(8 \%)$, in teen population the total number of cases were $81(14 \%)$, in young population the total number of cases were $103(18 \%)$, in adult population $277(50 \%)$ cases were seen, in seniors $53(10 \%)$ of cases.

Table 1 shows the number of poisoning cases with respect to age group.

Table 1: Age group wise distribution of patients

\begin{tabular}{lll}
\hline Age group & Total number of patients & Percentage (\%) \\
\hline Child $(0-9)$ & 43 & 8 \\
Teen $(10-19)$ & 81 & 14 \\
Young (20-24) & 103 & 18 \\
Adult $(25-29)$ & 277 & 50 \\
Seniors $(>60)$ & 53 & 10 \\
\hline
\end{tabular}

Table 2: Cause of exposure

\begin{tabular}{lll}
\hline Cause of exposure & Total number of patients & Percentage (\%) \\
\hline Suicidal & 360 & 64 \\
Accidental & 189 & 34 \\
Occupational & 6 & 1 \\
Others & 3 & 1 \\
\hline
\end{tabular}

\section{Based on cause of exposure}

Out of 557 cases identified; based on the Cause of exposure, suicidal cases were 360(64\%), accidental cases were 189(34\%), occupational cases were $6(1 \%)$, and others were $3(1 \%)$ (table 2 ).

Table 2 shows the poisoning cases with respect to the cause of exposure

\section{Based on the nature of poisoning}

Out of 557 poison cases identified; based on the nature of poison consumed, 64 subjects were consumed the insecticide poison, 93 patients exposed to the household poisons, 16 poison cases were admitted because of food, 86 cases got affected by bites and more number of poison 296 of cases were seen in others group.

Table 3 shows the type of poisoning

\section{Classification based on the antidote given $(n=557)$}

Out of 557 subjects identified based on the antidote given for the patients; A. C was given to 175 patients, $\mathrm{A}$. $\mathrm{C}+\mathrm{NAC}$ was given to 84 patients, A. C+coconut oil was given to 6 patients, ASV was given to 54 patients, other types of antidote was given to 125 patients, unknown antidotes was received by 113 patients.

Table 4 shows the types of antidote given for the poison cases

\section{Classification based on the outcomes $(n=557)$}

Out of 557 poison cases identified based on the outcomes, 440 patients recovered, 111 patients recovered with the sequel and 7 patients were expired.

Table 5 shows the number of poison cases and its outcomes. 
Table 3: Nature of poison

\begin{tabular}{lll}
\hline Nature of poison & Total number of patients & Percentage (\%) \\
\hline Insecticide & 64 & 12 \\
Household & 93 & 17 \\
Food & 16 & 3 \\
Bites & 86 & 15 \\
Others & 296 & 53 \\
\hline
\end{tabular}

Table 4: Types of antidote

\begin{tabular}{|c|c|c|}
\hline Antidote & Total number of patients & Percentage (\%) \\
\hline A. $\mathrm{C}$ & 175 & 32 \\
\hline A. $\mathrm{C}+\mathrm{NAC}$ & 84 & 15 \\
\hline A. $\mathrm{C}+$ Coconut oil & 6 & 1 \\
\hline ASV & 54 & 10 \\
\hline Others & 125 & 22 \\
\hline Unknown & 113 & 20 \\
\hline
\end{tabular}

A. C-activated charcoal, NAC-n-acetyl cysteine, ASV-anti snake venom

Table 5: Outcomes

\begin{tabular}{lll}
\hline Outcome & Total number of patients & Percentage (\%) \\
\hline Recovery & 440 & 79 \\
Sequel & 111 & 20 \\
Death & 7 & 1 \\
\hline
\end{tabular}

\section{DISCUSSION}

The current study included 557 poison cases. In this 521 cases were retrospective and 36 cases were prospective. They were selected based on the inclusion and exclusion criteria.

In this study period, the total number of poison cases documented in the PSG Hospitals, Coimbatore was 557. In this maximum number of the cases were seen in the year $2015(0.29 \%)$, followed by the years 2016(0.24\%), 2017(0.19\%), 2013(0.21\%), 2014(0.20\%), 2012(0.19\%). It shows that poisoning admissions were increasing in this place.

Data analysis shows that poisoning cases were prominent in the female population. The predominance in female sex in poisoning may be due to different psychological stresses and family issues when compared to males [7, 9].

Analysis of age wise distribution showed the predominance of an adult population because of emotional and physical changes parental loss, domestic disputes and addiction. Followed by young (20-24) female were predominant because of divorce, breakdown in family relationships teen(10-19) comprised of $81(14 \%)$ of cases due to less marks in exams, school reports, dominative words by parents seniors $(>60)$ consists of $53(10 \%)$ cases because of depression, ignored by their son/daughters and less number of cases were seen in child(0-9) contains $43(8 \%)$ accidental consumption were seen because of hyperactivity by the children and improper storage of the substances [3]

Based on the cause of exposure of victims, suicidal poisoning comprised of (64\%) accidental poisoning comprised $34 \%$ and occupational poisoning consists of $1 \%$. Cause of suicidal poisoning were poverty, psychiatric illness, etc. in case of the children and seniors most of the poisoning were due to improper storage of household chemicals and medicines. Occupational poisoning is due to the snake capturer, long term use of medicines, etc [8].

The various types of poisoning included in the study were an insecticide, household, food, bites, and others which include medicines and synthetic yellow cow dung powder. In this study others was the most commonly used for self-poisoning 296(53\%) cases. Household was the second common poisoning after others. Bites belong to third in poisoning which comprise of $86(15 \%)$ cases. It was found that only $16(3 \%)$ case suffering from food poison.

Our findings revealed that most of the patients 32\% received activated charcoal, $22 \%$ of the patients received by others which contains $\mathrm{N}$-acetyl cysteine, tamarind water, etc., the combination of activated charcoal and $\mathrm{N}$-acetyl cysteine was received by $15 \%$ of the poison cases, which is mostly given for medicine poisoning and synthetic yellow cow dung powder poison. Compared to other antidotes received by the patient only $10 \%$ of poison cases received anti-snake venom.

In this study, based on the outcome maximum number of the patients $79 \%$ was recovered which implies they are cured and safe. Second place occupied by the sequel which $20 \%$ of the victims; says they have been recovered but the affected part not yet cured and only $1 \%$ of poison cases were expired; which is mainly because of long term intake of medicine induced toxicity, followed by multiple organ failure induced by bites [4].

Statistical analysis has shown that there is a significance between gender with the nature of poison; shows that female population were affected more; in age group with nature of poison, adult group were seen more; in nature of poison with outcome, others group of population were identified more in number; and $>2-5 \mathrm{~h}$ time elapsed was identified maximum in time elapsed with outcome.

\section{CONCLUSION}

From this study, we can possibly continue to work on providing psychological counseling and rehabilitation to the patients who attempted suicide. Though medicine and household poisoning were seen more in this zone, so it is important to counsel the relatives of the patients to store the household chemicals and medicines in a safe place and strict rules to be implemented in selling these synthetic cow dung powders and also to advice the people to avoid storage of these powders.

\section{AUTHORS CONTRIBUTIONS}

All the author have contributed equally

\section{CONFLICT OF INTERESTS}

Declared none

\section{REFERENCES}

1. Subash Vijaya Kumar, B Venkateswarlu, M Sasikala, G Vijay Kumar. A study on poisoning cases in a tertiary care hospital. J Nat Sci Biol Med 2010;1:35-9.

2. Tejas Prajapati, Kartik Prajapti, RN Tandon, Saumil Merchant. A study of poisoning cases excluding animal bites at civil hospital, Ahmedabad. J Indian Acad Forensic Med 2013;35:2. 
3. Mehdi Oraie, Mir-Jamal Hosseini, Mina Islambulchilar, SeyedHasan Hosseini, Mehdi Ahadi-Barzoki, Habib Sadr, et al. A study of poisoning cases admitted to the university hospital emergency department in Tabriz, Iran. Drug Res 2017;67:183-8.

4. Siddaraya Hanjagi, Sachin Gudage. Study poisoning cases at alameen medical college, vijayapur, Karnataka. Int J Biomed Adv Res 2016;7:359-62.

5. DK Suneetha, J Inbanathan, Sowmya Kannoth, PK Reshma, MS Shashank. Profile of rat killer poisoning cases in a tertiary care hospital at Mysore. Int J Sci Study 2016;3:264-7.

6. Khaja Mohideen Sherfudeen, Senthil Kumar Kaliannan, Pavan Kumar Dammalapati. Cow dung powder poisoning. Indian J Crit Care Med 2015;19:684-6.
7. Erhan Zohre MD, Cuneyt Ayrik MD, Seyran Bozkurt MD, Ataman Kose MD, Huseyin Narci MD, Ibrahim Cevik MD, et al. Retrospective analysis of poisoning cases admitted to the emergency medicine. Arch Iran Med 2015;18:117-22.

8. Vivekanandan K, Bhavya E, K Punitha, N Vijay Anand. A study on poison cases and their management along with poison awareness educational strategies. Asian J Pharma Clin Res 2012;5:71-3.

9. JJ Rasimas, Erica E Smolcic, Courtney M Sinclair. Themes and trends in international self-poisoning: perspectives from critical care toxicology. Psychiatr Res 2017;255:30413. 